\title{
REALIZATION OF REVERSE MOTION OF THE MODEL OF A SEMITRAILER ROAD TRAIN
}

\author{
Dmitry Tatievskyi \\ Department of Software of Automated Systems \\ Zaporizhzhia State Engineering Academy, \\ 226 Soborny ave., Zaporizhzhia, Ukraine, 69006 \\ dtdissert@gmail.com
}

\begin{abstract}
The complexity of controlling the road train is due to pronounced nonlinearities, as well as the instability of the control object under reverse motion, often leading to a phenomenon known as jackknifing. Because of this, the task of controlling their motion is relevant, both from the theoretical point of view and from the point of view of the practical implementation of software motion with given constraints.

The task of controlling the motion of a road train with a semitrailer under the assumption of non-holonomic constraints (the absence of lateral slippage of support wheels) has a great theoretical and applied significance. Research in this field is stimulated by numerous applied problems.

For road trains, the location of the towing device behind the rear axle (off-axle hitching model) is quite typical. This model is used in this study. For this model, management and planning methods are proposed, using a diverse mathematical apparatus. Among the most frequently used methods, let's select the methods of feedback linearization and chain systems, and methods are used, which are exclusively due to the geometric features of the model kinematics formulated in cascade form. Synthesis of control laws can be performed after the linearization of the model by state feedback, using the Lie algebra apparatus, fuzzy logic, using linear-quadratic controllers, nilpotent approximation, and so on.

Studies have been carried out on the state of solving the problem associated with the reverse motion of a road train consisting of a hauler and a semitrailer with a coupling sideshift. The synthesized stabilizing control allowed to study the features of such model, determined by its linear dimensions and dynamic parameters.

In this study, one of the possibilities of stabilizing the reversal motion of the dynamic model of a two-link road train on a rectilinear and circular track is considered. Synthesis of the stabilizing control is obtained for the case of rectilinear motion, hauler, stable circular stationary regimes are realized. The obtained theoretical relationships that determine the properties of the crew's ability to rotate when moving in reverse, allow the latter to be used when the algorithm is implemented.
\end{abstract}

Keywords: automation, wheel, three-axle road train model, semitrailer, rectilinear motion, reverse motion, hauler, control, Unity $3 \mathrm{D}$

\section{Introduction}

It is known from practice that the aspiration of a wheel on a pendant suspension occupies a position in which it rolls after the articulation point (with backward sideshift) $[1,2]$. The instability of the motion with the forward sideshift corresponds to the motion of the saddle road train by the reverse, has a divergent (monotonous) character, the behavior of the semitrailer in this case is similar to the behavior of the inverted pendulum [3-6]. Known approaches to stabilize the motion of the semi-trailer in reverse are presented in $[7,8]$.

One of the possibilities for stabilizing such motion is associated with the introduction of a control action, which depends on the magnitude of the perturbations in one or more phase variables of the system (synthesis of systems with feedback on the state).

Let's suppose that the current value of the angle of folding is parried by turning the wheel axle of the semitrailer (to reduce the angle of misalignment between the longitudinal axis of the hauler and the longitudinal plane of the semitrailer wheels). Moreover, the amount of rotation of the axis will be proportional to the value of the angle of folding (coefficient of proportionality $\mathrm{k}$ ).

\section{Materials and methods}

The stability and rotatability of the bicycle model of a three-axle semitrailer (both linear and nonlinear) has been studied in detail $[9,10]$ for the case of forward motion. 
Let's select system parameters:

$-\mathrm{v}$ - longitudinal component of the hauler's center of mass;

$-\mathrm{a}, \mathrm{b}-$ the distance from the hauler's center of mass to the centers of the front (controllable) axle and the hauler's rear axle;

$-\mathrm{c}-$ the distance from the hauler's center of mass to the point of coupling with the second link;

$-d_{1}$ - distance from the center of mass of the second link to the point of coupling with the hauler; drag coefficients on the axes $\left(\mathrm{k}_{1} ; \mathrm{k}_{2} ; \mathrm{k}_{3}\right)$;

$-\theta$ - angle of rotation of the controlled module;

$-\mathrm{X}_{1}, \mathrm{X}_{2}, \mathrm{X}_{3}$ - longitudinal forces on the axes;

$-\mathrm{m}, \mathrm{J}-$ mass and the central moment of inertia of the hauler;

$-\mathrm{v}, \mathrm{u}-$ longitudinal and transverse projections of the velocity vector of the center of mass on the axis, connected with the hauler;

$-\omega-$ angular velocity of the hauler, relative to the vertical axis;

$-\mathrm{m}_{2}, \mathrm{~J}_{2}-$ mass and the central moment of inertia of the second link;

$-v_{1}, u_{1}-$ longitudinal and transverse projections of the velocity vector of the center of mass of the second link;

$-\varphi$ - folding angle (the angle between the longitudinal axis of the hauler and the semitrailer).

The design scheme of the three-axle road train model is shown in Fig. 1.

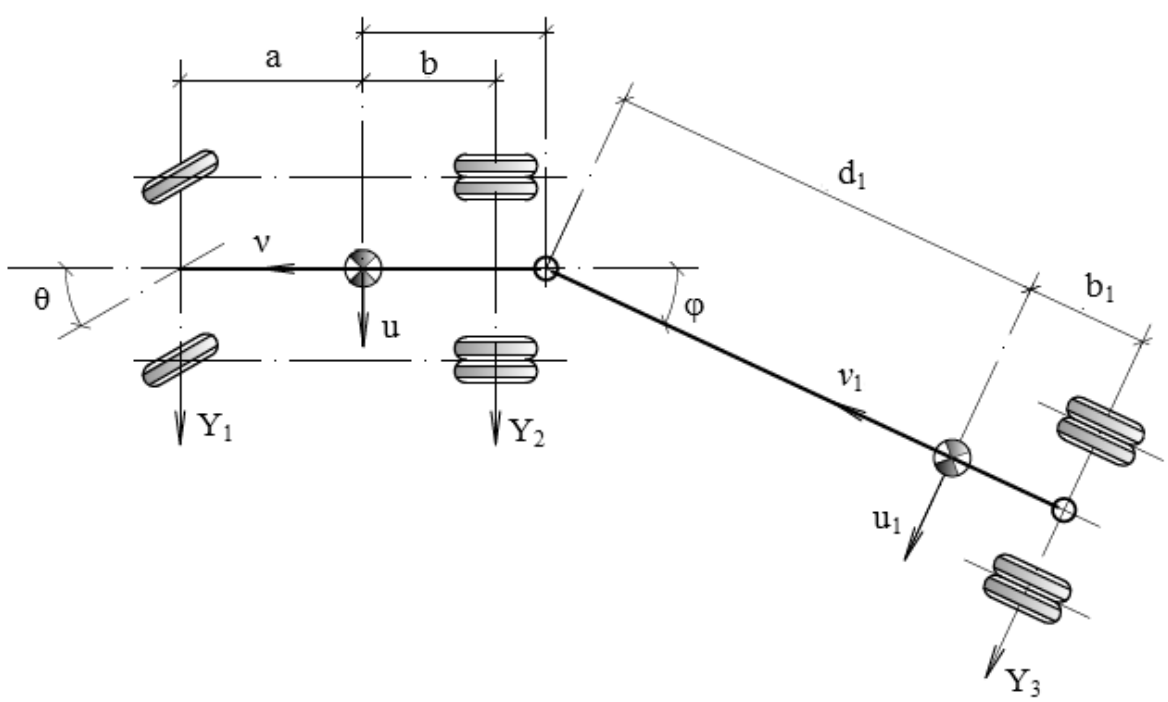

Fig. 1. The design scheme of the model of a three-axle road train

To implement the reverse motion model, some of the geometric design parameters of the model will take negative values: $c, d_{l}, b_{l}$. In addition, the hauler's rear axle will be the first, and the steerable hauler wheel module will become the second axle in the updated model scheme.

The linearized system of equations of motion has the form:

$$
\begin{aligned}
& -\mathrm{m} \cdot(\mathrm{U}+\omega \cdot \mathrm{v})+\mathrm{Y}_{1}+\mathrm{Y}_{3}+\mathrm{m}_{2} \cdot \mathrm{d}_{1} \cdot \Omega-\mathrm{m}_{2} \cdot \mathrm{d}_{1} \cdot \mathrm{PP}+ \\
& +\mathrm{Y}_{2}-\mathrm{m}_{2} \cdot \mathrm{U}+\mathrm{m}_{2} \cdot \mathrm{c} \cdot \Omega-\mathrm{m}_{2} \cdot \omega \cdot \mathrm{v}=0 \\
& \mathrm{c} \cdot \mathrm{m}_{2} \cdot \omega \cdot \mathrm{v}-\mathrm{b} \cdot \mathrm{Y}_{2}-\mathrm{J} \cdot \Omega+\mathrm{c} \cdot \mathrm{m}_{2} \cdot \mathrm{d}_{1} \cdot \mathrm{PP}- \\
& -\mathrm{c} \cdot \mathrm{m}_{2} \cdot \mathrm{d}_{1} \cdot \Omega+\mathrm{a} \cdot \mathrm{Y}_{1}+\mathrm{c} \cdot \mathrm{m}_{2} \cdot \mathrm{U}-\mathrm{m}_{2} \cdot \mathrm{c}^{2} \cdot \Omega+\mathrm{c} \cdot \mathrm{Y}_{3}=0 \\
& \quad-\mathrm{J}_{2} \cdot(\Omega-\mathrm{PP})-\mathrm{L}_{1} \cdot \mathrm{Y}_{3}+\mathrm{d}_{1} \cdot \mathrm{m}_{2} \cdot \mathrm{U}+\mathrm{d}_{1} \cdot \mathrm{m}_{2} \cdot \mathrm{U}+ \\
& \quad+\mathrm{d}_{1} \cdot \mathrm{m}_{2} \cdot \omega \cdot \mathrm{v}-\mathrm{d}_{1}^{2} \cdot \mathrm{m}_{2} \cdot \mathrm{PP}-\mathrm{c} \cdot \mathrm{m} \cdot \mathrm{d} \cdot \Omega=0
\end{aligned}
$$


where $U$ - the derivative of the lateral component of the center of mass; $\Omega$ - the derivative of the angular velocity with respect to the vertical axis; PP - angular acceleration of the rear link, while:

$$
\mathrm{J}_{2}=0,8 \cdot \mathrm{m} \cdot \mathrm{d}_{1} \cdot \mathrm{b}_{1}, \quad \mathrm{~J}=0,35 \cdot \mathrm{m} \cdot \mathrm{a} \cdot \mathrm{c} .
$$

Drift angles (reduced) on the axes:

$$
\begin{gathered}
\delta_{1}=-(\mathrm{a} \cdot \omega+\mathrm{u}) / \mathrm{v} ; \\
\delta_{2}=\theta+(\mathrm{b} \cdot \omega-\mathrm{u}) / \mathrm{v} \\
\delta_{3}=\mathrm{k} \cdot \phi-\left(\mathrm{v} \cdot \phi-\omega \cdot \mathrm{c}+\mathrm{u}-(\omega-\Phi) \cdot \mathrm{d}_{1}-(\omega-\Phi) \cdot \mathrm{b}_{1}\right) / \mathrm{v} .
\end{gathered}
$$

Drift forces (the linear drift hypothesis of I. Rokar) [11]:

$\mathrm{Y}_{1}=\mathrm{k}_{\mathrm{i}} \cdot \delta_{\mathrm{i}}(\mathrm{i}=1,2,3)$

The condition of static stability of the system can be reduced to identifying the sign of the free term of the characteristic equation, which in a stable system must be positive. All the calculations below are performed in the Maple system and will be accompanied by appropriate illustrations. Also, the Unity 3D system is used for modeling, the illustration of which, also, is given below.

The free term of the characteristic equation has the form (4):

$$
\begin{aligned}
& -\mathrm{k}_{3} \cdot \mathrm{v} \cdot(\mathrm{k}-1) \cdot\left(\mathrm{L}_{1} \cdot \mathrm{k}_{1} \cdot \mathrm{k}_{1} \cdot(\mathrm{a}+\mathrm{b})^{2}+\right. \\
& +\left(\left(\mathrm{b} \cdot \mathrm{m} \cdot \mathrm{L}_{1}+\mathrm{b}_{1} \cdot(\mathrm{b}-\mathrm{c}) \cdot \mathrm{m}_{2}\right) \cdot \mathrm{k}_{2}-\right. \\
& \left.\left.-\left(\mathrm{b}_{1} \cdot(\mathrm{a}+\mathrm{c}) \cdot \mathrm{m}_{2}+\mathrm{L}_{1} \cdot \mathrm{a} \cdot \mathrm{m}\right) \cdot \mathrm{k}_{1}\right) \cdot \mathrm{v}^{2}\right)
\end{aligned}
$$
ve values.

Let's note that $\mathrm{L}_{1}=\mathrm{d}_{1}+\mathrm{b}_{1}<0$, since these design parameters of the model have negati-

For $\mathrm{k}<1$, the rectilinear motion is structurally unstable. A necessary condition for stability is $\mathrm{k}>1$. Necessary and sufficient conditions for the stability of rectilinear motion (the reversal case) are very cumbersome and do not allow to estimate the region of stability in the parameter space. Therefore, stability analysis is carried out on the basis of a numerical definition of the set of eigenvalues of the matrix of a system of linear approximation.

For further visualization of the stabilization process and numerical integration of the initial nonlinear model, the following set of design parameters was used: $g=9.81 \mathrm{~m} / \mathrm{s}^{2} ; \mathrm{a}=3,376 \mathrm{~m}$; $\mathrm{b}=4.217 \mathrm{~m} ; \mathrm{bl}=-2.93 \mathrm{~m} ; \mathrm{dl}=-8.075 \mathrm{~m} ; \mathrm{s}=-3.376 \mathrm{~m} ; \mathrm{m}=6417 \mathrm{~kg} ; \mathrm{m}_{2}=41846 \mathrm{~kg} ; \mathrm{k}_{1}=300,000 \mathrm{~N} / \mathrm{rad}$; $\mathrm{k}_{2}=300,000 \mathrm{~N} / \mathrm{rad} ; \mathrm{k}_{3}=300,000 \mathrm{~N} / \mathrm{rad} ; \mathrm{kappa}_{1}=0.8 ; \mathrm{kappa}_{2}=0.8 ; \mathrm{kappa}_{3}=0.8$; theta $=0 ;$ phi $(0)=-0.2$ $\mathrm{rad} ; \mathrm{v}=1.5 \mathrm{~m} / \mathrm{s} ; \mathrm{KOL}=2.2 \mathrm{~m}$; kappa=1.7.

In this case, the initial folding angle is $\mathrm{phi}(0)=-0.2 \mathrm{rad}$; longitudinal motion velocity $1.5 \mathrm{~m} / \mathrm{s} ; \mathrm{k}=1.7$ - the control factor.

The coefficient matrix of a system of linear approximation in the neighborhood of unperturbed rectilinear motion:

$$
\text { Joo }:=\left[\begin{array}{cccc}
-135,2491507 & 687,1654087 & 1,067275933 & 11,18606823 \\
55,13762551 & -332,6505548 & -0,9032463789 & -9,466882286 \\
0 & 0 & 0 & 1 \\
60,64766584 & -365,3494942 & -1,749911398 & -18,34073803
\end{array}\right] \text {. }
$$

The characteristic equation has the form: 
$>$ chp:=linalg[charpoly](Joo,lambda);

chp $:=\lambda^{4}+486,2404435 \lambda^{3}+11548,28229 \lambda^{2}+57088,4035 \lambda+540,41218$;

>eigv:=evalf(solve(chp,lambda));

eigv: $=-0,09658173298,-6,786772386,-17,87285818,-461,4842312$.

Its roots lie in the left complex half-plane, which indicates the asymptotic stability of the rectilinear motion.

Independent numerical integration of the original nonlinear model (confirmation of stabilization of rectilinear motion by reverse) is performed for the following set of design parameters. Fig. 2 shows the fragments modeling the stabilization of rectilinear motion reversal in a Unity 3D environment.

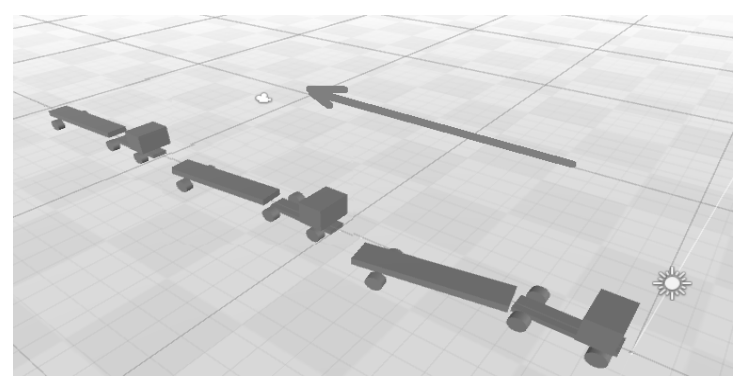

Fig. 2. Visualization of stabilization of reverse motion on a straight section

The stabilization process with respect to the folding angle is shown in Fig. 3.

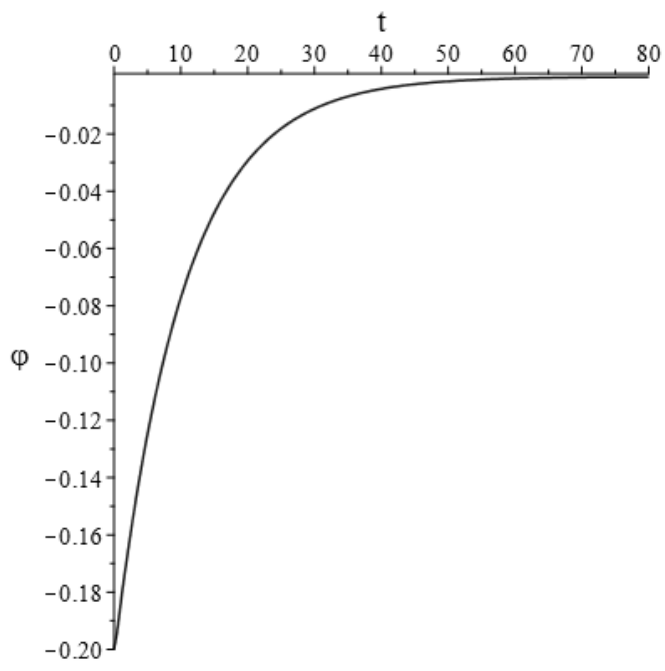

Fig. 3. The integral curve with respect to the folding angle when reverse motion by the reverse $(k=1.7)$

Fig. 4 illustrates the behavior of the system in the absence of control $(k=0)$, performed in the Unity system. in Fig. 5.

The graph of the corresponding integral curve with respect to the folding angle is illustrated

The development of the growth of initial perturbations with respect to the folding angle for $\mathrm{k}=0$ has a divergent monotonic character.

For the selected value of the control coefficient $\mathrm{k}=1.7$ in the longitudinal velocity range $\mathrm{v}=0.5-3 \mathrm{~m} / \mathrm{s}$, rectilinear reverse motion is asymptotically stable; at a constant non-zero steering angle of the wheel module of the hauler in the interval $\pm 0.5 \mathrm{rad}$, stable circular stationary modes of motion are realized.

The parameters of these stationary modes are described by two relations - direct rotatability and direct folding, which were previously known for the case of forward motion (hauler ahead of the semitrailer) $[12,13]$ : 


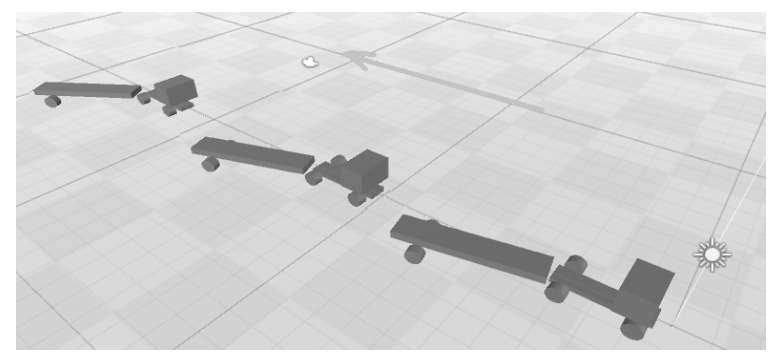

Fig. 4. Development of the folding process in the reverse motion of the road train (no control $\mathrm{k}=0$ )

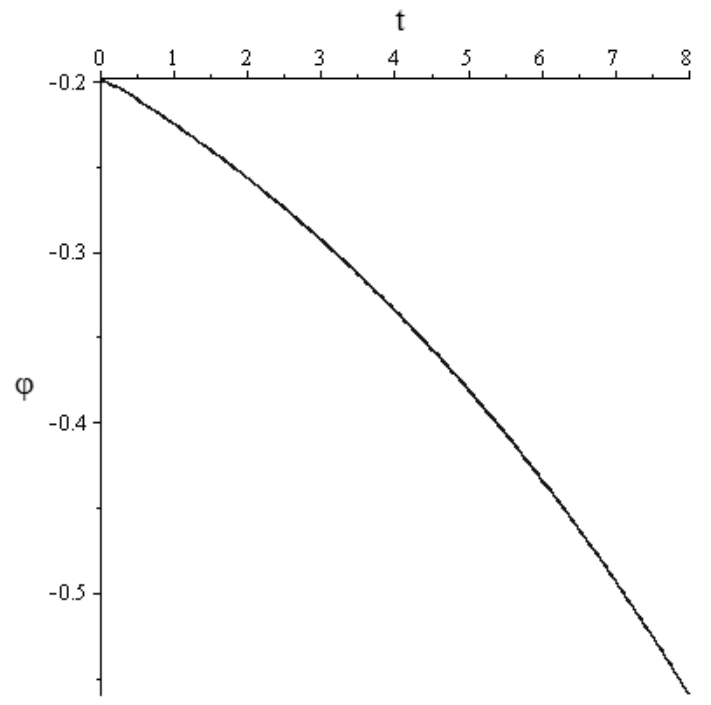

Fig. 5. Integral curve for the folding angle in the absence of control

$$
\begin{aligned}
& \theta=-\frac{1}{\mathrm{~L}_{1} \cdot \mathrm{R} \cdot \mathrm{k}_{1} \cdot \mathrm{k}_{2} \cdot(\mathrm{a}+\mathrm{b})} \cdot\left(\left(-\mathrm{L}_{1} \cdot \mathrm{R} \cdot \mathrm{a} \cdot \mathrm{g} \cdot \mathrm{k}_{1} \cdot \mathrm{m}-\mathrm{L}_{1} \cdot \mathrm{R} \cdot \mathrm{a} \cdot \mathrm{g} \cdot \mathrm{k}_{1} \cdot \mathrm{m}_{2}+\mathrm{L}_{1} \cdot \mathrm{R} \cdot \mathrm{b} \cdot \mathrm{g} \cdot \mathrm{k}_{2} \cdot \mathrm{m}+\right.\right. \\
& +\mathrm{L}_{1} \cdot \mathrm{R} \cdot \mathrm{b} \cdot \mathrm{g} \cdot \mathrm{k}_{2} \cdot \mathrm{m}_{2}-\mathrm{L}_{1} \cdot \mathrm{R} \cdot \mathrm{c} \cdot \mathrm{g} \cdot \mathrm{k}_{1} \cdot \mathrm{m}_{2}+\mathrm{R} \cdot \mathrm{a} \cdot \mathrm{d}_{1} \cdot \mathrm{g} \cdot \mathrm{k}_{1} \cdot \mathrm{m}_{2}-\mathrm{R} \cdot \mathrm{b} \cdot \mathrm{d}_{1} \cdot \mathrm{g} \cdot \mathrm{k}_{2} \cdot \mathrm{m}_{2}+ \\
& \left.\left.+\mathrm{R} \cdot \mathrm{c} \cdot \mathrm{d}_{1} \cdot \mathrm{g} \cdot \mathrm{k}_{1} \cdot \mathrm{m}_{2}+\mathrm{R} \cdot \mathrm{c} \cdot \mathrm{d}_{1} \cdot \mathrm{g} \cdot \mathrm{k}_{2} \cdot \mathrm{m}_{2}\right) \cdot \mathrm{a} \cdot \mathrm{y}\right)- \\
& -\frac{\mathrm{L}_{1} \cdot \mathrm{a}^{2} \cdot \mathrm{k}_{1} \cdot \mathrm{k}_{2}+2 \cdot \mathrm{L}_{1} \cdot \mathrm{a} \cdot \mathrm{b} \cdot \mathrm{k}_{1} \cdot \mathrm{k}_{2}+\mathrm{L}_{1} \cdot \mathrm{b}^{2} \cdot \mathrm{k}_{1} \cdot \mathrm{k}_{2}}{\mathrm{~L}_{1} \cdot \mathrm{R} \cdot \mathrm{k}_{1} \cdot \mathrm{k}_{2} \cdot(\mathrm{a}+\mathrm{b})} .
\end{aligned}
$$

The rotatability equation after simplifications is reduced to a dimensionless form, which formally coincides for the case of forward motion:

$$
\theta=-\frac{1}{\mathrm{R}}+\left(\frac{1}{\mathrm{~K}_{1}}-\frac{1}{\mathrm{~K}_{2}}\right) \cdot \mathrm{a}_{\mathrm{y}}
$$

For folding angle:

$$
\begin{aligned}
& \varphi=-\frac{1}{\mathrm{~L}_{1} \cdot \mathrm{R} \cdot \mathrm{k}_{1} \cdot(\mathrm{a}+\mathrm{b}) \cdot(\mathrm{k}-1) \cdot \mathrm{k}_{3}} \cdot\left(\mathrm{L}_{1} \cdot \mathrm{b} \cdot \mathrm{k}_{3} \cdot \mathrm{m} \cdot \mathrm{v}^{2}+\mathrm{L}_{1} \cdot \mathrm{b} \cdot \mathrm{k}_{3} \cdot \mathrm{m}_{2} \cdot \mathrm{v}^{2}-\right. \\
& -\mathrm{L}_{1} \cdot \mathrm{c} \cdot \mathrm{k}_{3} \cdot \mathrm{m} \cdot \mathrm{v}^{2}-\mathrm{a} \cdot \mathrm{d}_{1} \cdot \mathrm{k}_{1} \mathrm{~m}_{2} \cdot \mathrm{v}^{2}-\mathrm{b} \cdot \mathrm{d}_{1} \cdot \mathrm{k}_{1} \mathrm{~m}_{2} \cdot \mathrm{v}^{2}-\mathrm{b} \cdot \mathrm{d}_{1} \cdot \mathrm{k}_{3} \mathrm{~m}_{2} \cdot \mathrm{v}^{2}+ \\
& +\mathrm{c} \cdot \mathrm{d}_{1} \cdot \mathrm{k}_{3} \mathrm{~m}_{2} \cdot \mathrm{v}^{2}+\mathrm{L}_{1} \cdot \mathrm{a}^{2} \cdot \mathrm{k}_{1} \cdot \mathrm{k}_{3}+\mathrm{L} \cdot \mathrm{a} \cdot \mathrm{b} \cdot \mathrm{k}_{1} \cdot \mathrm{k}_{3}+\mathrm{L}_{1} \cdot \mathrm{a} \cdot \mathrm{b}_{1} \cdot \mathrm{k}_{1} \cdot \mathrm{k}_{3}+\mathrm{L}_{1} \cdot \mathrm{a} \cdot \mathrm{c} \cdot \mathrm{k}_{1} \cdot \mathrm{k}_{3}+ \\
& \left.+\mathrm{L}_{1} \cdot \mathrm{a} \cdot \mathrm{d}_{1} \cdot \mathrm{k}_{1} \cdot \mathrm{k}_{3}+\mathrm{L} \cdot \mathrm{b} \cdot \mathrm{b}_{1} \cdot \mathrm{k}_{1} \cdot \mathrm{k}_{3}+\mathrm{L}_{1} \cdot \mathrm{b} \cdot \mathrm{c} \cdot \mathrm{k}_{1} \cdot \mathrm{k}_{3}+\mathrm{L}_{1} \cdot \mathrm{b} \cdot \mathrm{d}_{1} \cdot \mathrm{k}_{1} \cdot \mathrm{k}_{3}\right) .
\end{aligned}
$$

In the equation for the folding angle, an additional factor $1 /(\mathrm{k}-1)$ appears. 
After simplifications, it is reduced to a dimensionless form:

$$
\varphi=\frac{\left(\frac{1}{\mathrm{~K}_{1}}-\frac{1}{\mathrm{~K}_{3}}\right) \cdot \mathrm{a}_{\mathrm{y}}}{\mathrm{k}-1}-\frac{\mathrm{a}+\mathrm{c}+\mathrm{L}_{1}}{\mathrm{R} \cdot(\mathrm{k}-1)},
$$

where $\mathrm{K}_{1}=\mathrm{k}_{1} / \mathrm{Z}_{1} ; \mathrm{K}_{2}=\mathrm{k}_{2} / \mathrm{Z}_{2}-$ dimensionless drift coefficients.

$$
\mathrm{Z}_{1}=\frac{\mathrm{m} \cdot \mathrm{g} \cdot \mathrm{b}-\frac{\mathrm{m}_{2} \cdot \mathrm{g} \cdot \mathrm{b}_{1} \cdot(\mathrm{c}-\mathrm{b})}{\mathrm{L}_{1}}}{\mathrm{l}} ;
$$

Let's define the required radius of curvature and the longitudinal component of the hauler's center of mass $\mathrm{R}=50 \mathrm{~m}, \mathrm{v}=1.5 \mathrm{~m} / \mathrm{s}$, when moving reverse. From the rotatability and folding equations, let's obtain the required value of the angle of rotation of the steering wheel module of the hauler and the established folding angle between the hauler and the semitrailer:

$$
\begin{gathered}
\theta=-0,15 \mathrm{rad} \\
\phi=0,31 \mathrm{rad} .
\end{gathered}
$$

The value of the phase variables corresponding to the stationary mode of motion is confirmed, both on the basis of iterative methods and on the basis of independent numerical integration. The stability of stationary circular motion regimes is investigated on the basis of a numerical definition of a set of eigenvalues of the matrix of a linear approximation system.

Circular stationary mode parameters:

$$
\begin{gathered}
\{\omega=0,02999999998, \phi=0,3178570910, \mathrm{u}=-0,1045886390\} ; \\
{[\omega]=1 / \mathrm{s},[\phi]=\operatorname{rad},[\mathrm{u}]=\mathrm{m} / \mathrm{s} .}
\end{gathered}
$$

The corresponding matrix of linear approximation:

$$
\text { Joo }:=\left[\begin{array}{cccc}
-135,2491507 & 687,1654087 & 1,067275933 & 11,18606823 \\
55,13762551 & -332,6505548 & -0,9032463789 & -9,466882286 \\
0 & 0 & 0 & 1 \\
60,64766584 & -365,3494942 & -1,749911398 & -18,34073803
\end{array}\right] \text {. }
$$

Characteristic equation:

$>$ chp:=linalg[charpoly](Joo,lambda);

chp: $=\lambda^{4}+486,2404435 \lambda^{3}+11548,28229 \lambda^{2}+57088,4035 \lambda+5406,41218$.

The roots of the equation indicate the stability of the circular motion regime:

> eigv:=evalf(solve(chp,lambda));

eigv: $=-0,0965817295,-6,786772386,-17,87285818,-461,4842312$. 
An illustration of the results of numerical integration of the equations of motion of a nonlinear model of a road train, with control in the Unity 3D system, is shown in Fig. 6.

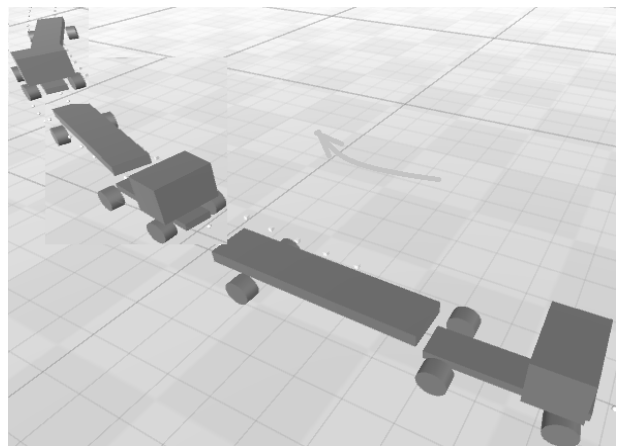

Fig. 6. Trajectory and configuration of the road train with reverse motion $(\mathrm{v}=1.5 \mathrm{~m} / \mathrm{s}, \theta=-0.15)$, case of control of the semi-trailer axle $(\mathrm{k}=1.7)$

To simplify the simulation of the dynamics of the road train, an application in $\mathrm{C} \#$ is developed. The application allows to automate the script in Maple language, the ability to enter different values of the model in interactive mode and promptly run the script for execution. The application is implemented through the use of the OpenMaple API, which provides access to Maple libraries from Windows applications and allows to run scripts written in the built-in language of the Maple system from the $\mathrm{C}$ \# application. From the displayed phase portraits, one can judge the stability of stationary modes of motion and the ability to inscribe a road train into the allotted corridors during maneuvering. Also, it is possible to edit the template for the Maple script, in order to obtain the necessary information.

In this case, the application stores the necessary information for the numerical integration of a system of differential equations to generate the necessary control information.

A fragment of the working application is shown in Fig. 7.
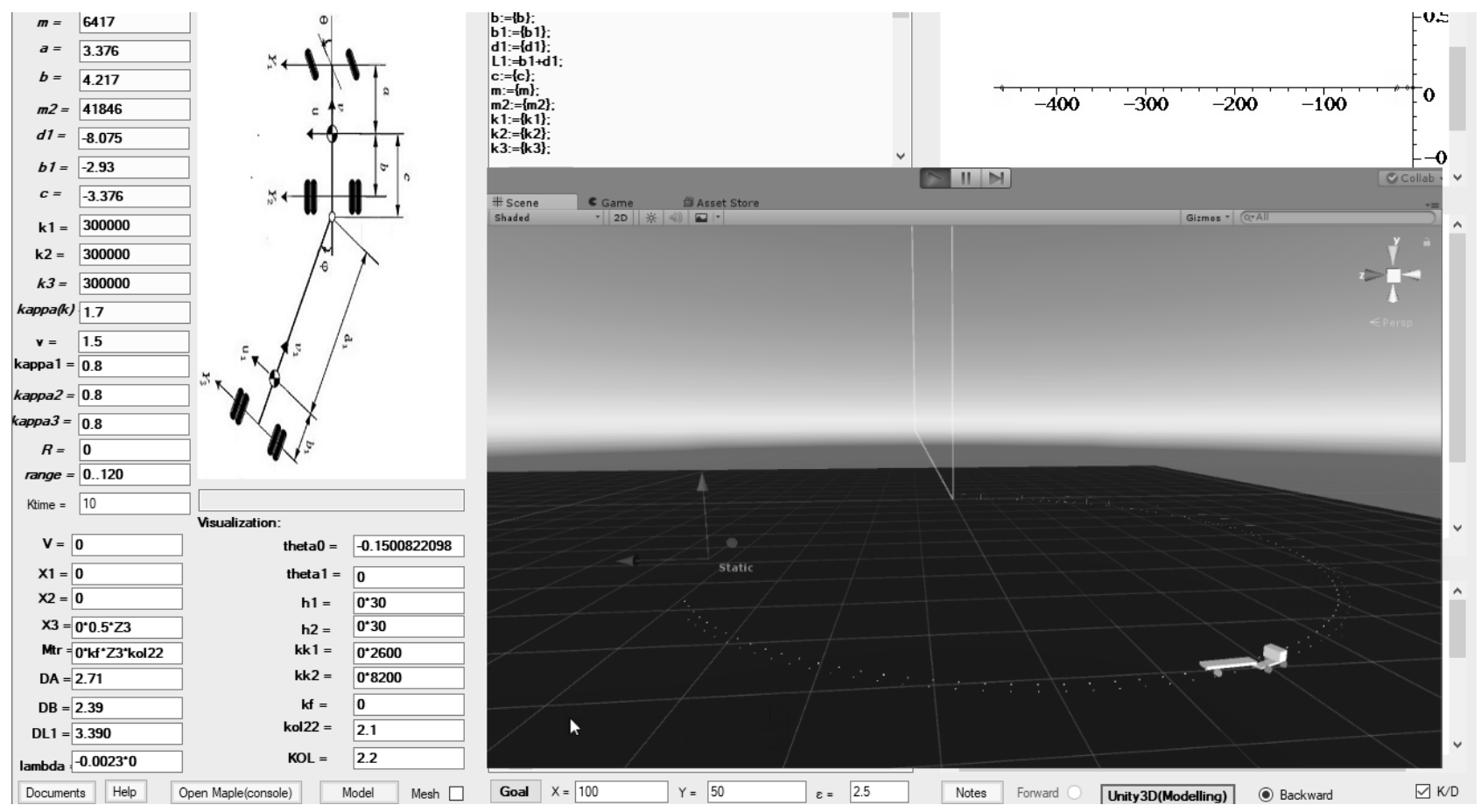

Fig. 7. Fragment of the application for automation and simulation of the reverse motion of the road train 
The script written for the Unity 3D system receives control information and visualizes the motion of the road train. So, in json format, it contains the trajectory coordinates of the hauler and trailer, the folding angle and rotation angle of the wheel module at fixed time intervals.

In scene mode, it is possible to monitor the change of parameters over time.

\section{Conclusions}

1. The review of existing approaches to the solution of the problem of stabilizing the reverse motion of a road train consisting of a hauler and a semi-trailer with a coupling sideshift is made.

2. The synthesis of stabilizing control is realized, both for the case of rectilinear motion, and in the presence of a constant non-zero steering angle for the steerable wheels of the hauler, for stable circular stationary regimes.

3. The features of the behavior of the dynamic model, determined by its geometry and dynamic parameters, are studied.

4. Comparison of the characteristics, the established conditions of the road train, obtained on the basis of analytical relationships and independent numerical integration, confirm the feasibility of implementing the program motion of the road train when moving in reverse.

Thus, it is possible to provide programmed motion along a path that will consist of parts of circular trajectories of a given radius and rectilinear sections. The implementation of the corresponding software motion will be considered in subsequent work. Also, it is planned to check the possibility of stabilizing the full dynamic model due to the control stabilizing the non-holonomic kinematic model.

\section{References}

[1] Lobas, L. G., Verbickii, V. G. (1990). Kachestvennie i analiticheskie metodi v dinamike kolesnih mashin. Kyiv: Naukova dumka, 232.

[2] Velmagina, N. A., Verbickii, V. G. (2011). Analiz avtokolebaniy kolesnogo modulya v pryamolineynom rezhime dvizheniya. Mehanika tverdogo tela, 41, 100-108.

[3] Kapitsa, P. L. (1951). Dinamicheskaya ustoychivost' mayatnika pri koleblyushheysya tochke podvesa. Zhurnal eksperimental'noy i tekhnicheskoy fiziki, 21, 588-607.

[4] Kapica, P. L. (1951). Mayatnik s vibriruyuschim podvesom. Uspekhi fizicheskikh nauk, 44, 7-20.

[5] Arnold, V. I. (2009). Ustoichivost perevernutogo mayatnika i shveinaya mashinka Kapici. Matematicheskoe ponimanie prirodi. Moscow: MCNMO, 146.

[6] Arnold, V. I. (1990). Teoriya katastrof. Moscow: Nauka, 120.

[7] Verbickii, V. G., Zagorodnov, M. I. (2007). Predelenie i analiz ustoychivosti krugovykh statsionarnykh rezhimov dvizheniya modeli sedel'nogo avtopoezda. Vestnik Doneckogo instituta avtomobilnogo transporta, 1, 10-19.

[8] Moisya, D. L., Bumaga, A. D. (2007). Opredelenie manevrennosti i analiz ustoychivosti dvizheniya modeli sedel'nogo avtopoezda. Vestnik Doneckogo instituta avtomobilnogo transporta, 3, 10-19.

[9] Ellis, J. R. (1975).Vehicle Dynamics. Moscow: Mashinostroenie, 216.

[10] Troger, H., Zeman, K. (1984). A Nonlinear Analysis of the Generic Types of Loss of Stability of the Steady State Motion of a Tractor-Semitrailer. Vehicle System Dynamics, 13 (4), 161-172. doi: $10.1080 / 00423118408968773$

[11] Rokar, I. (1959). Neustoichivost v mehanike. Avtomobili, samoleti, visyachie mosti. Moscow: IIL, 288.

[12] Kravchenko, A. P., Verbitskii, V. G., Zagorodnov, M. I., Bannikov, V. O., Sakno, O. P., Efimenko, A. N. et. al. (2010). On the problem of the steerability analysis of the automobile non-linear model. Naukovi visti Dalivskogo universitetu, 1.

[13] Pauwelussen, J. P., Anghelache, G., Theodorescu, D., Schmeitz, A. Yaw stability of articulated trucks. Leonardo DaVinci, module 10. 